\title{
THE PROJECT MANAGEMENT OF WATER SUPPLY COMPLEXES RECONSTRUCTION ON THE BASIS OF DECISION SUPPORT SYSTEMS
}

\author{
Anatoliy J. Gaida, Tigran G. Grigorian, Yuriy N. Kharitonov, Volodymyr K. Koshkin
}

\author{
Department of Information Control Systems and Technologies \\ Admiral Makarov National University of Shipbuilding \\ ave. Heroiv Staligradu, 9, Mykolaiv, 54000, Ukraine \\ e-mail: cetus@ukr.net, grigorian.tigran@gmail.com,uru888@yandex.ru,koshkin-vladimir@mail.ru
}

\begin{abstract}
The problems of managing projects of water supply system reconstruction are considered. The characteristics of such systems and especially the processes of planning and implementation of water supply systems reconstruction projects were analyzed. The necessity of sharing the methods of projects value assessing according to their social significance and economic benefit expectations are identified. On the basis of the fulfilled research a structural model of automated decision support system in project management of water supply systems reconstruction is proposed. The model is based on the use of the weighted sum method and assessment the current states of projects by the means of a neural network classifier. Copyright (C) Research Institute for Intelligent Computer Systems, 2014. All rights reserved.
\end{abstract}

Keywords: project management, reconstruction projects, water supply system, decision support system, neural network, weighted sum method.

\section{INTRODUCTION}

One of the major problems that determine the further society development is the efficient use of water resources [1]. One aspect of this problem is to develop a set of activities related to the provision of drinking water to municipalities [2-5]. In Ukraine the problem is exacerbated by significant physical and moral deterioration of the basic elements of water supply systems (WSS), inequality of the technical and technological parameters of WSS to the existing standards and norms, lack of the necessary resources for the renovation and realization of evidence-based recommendations for the WSS reconstruction projects implementation $[6,7]$.

Another pressing problem associated with providing municipalities with water, is the WSS reconstruction projects planning and implementation. This is due to the need for not only continuous monitoring and analysis the infrastructure of WSS states, but also for realizations of preventive and emergency repairs. Although the income of the projects is determined by project costs the feature of decision making is connected to taking in the account general water supply tariffs that are usually united. It forces project managers to take in the account not only economical factors, but also social characteristics of projects and customers during portfolio creation. In this case, it is advisable to use the value-driven project management methodology in order to improve the efficiency of these activities as this methodology has shown good results for a long period of time.

\section{CURRENT STATUS OF VALUE-DRIVEN DECISION MAKING IN THE WSS RECONSTRUCTION}

The complexity of the problem domain (a lot of technical parameters and characteristics of the WSS, structures complexity, spatial components, a significant number of participants and stakeholders of the projects, high social importance of the projects etc) requires the development of a decision support (DSS) system and corresponding models, which will provide the decision-maker with valuedriven information necessary for the WSS reconstruction projects planning and implementtation.

Currently there is a considerable amount of research devoted to improvement the efficiency of the WSS [8-10]. IT-technology is used widely in different systems of municipal water supplies in small towns and also in big cities [11-13]. Thus, in $[13,14]$ the architecture and main elements of a typical control of the municipal WSS are considered. The WSS consists of a central computer, the primary 
sensors and electromechanical control devices, means for transmitting and receiving signals [12].

There is a wide range of project management and portfolio management software systems. These systems include both Microsoft Project Server ${ }^{\circledR}$ and Microsoft Project Professional $^{\circledR}$, Oracle Primavera Enterprise Portfolio Management ${ }^{\circledR}$ and open systems like Basecamp ${ }^{\circledR}$, TeamLab $^{\circledR}$, Teamwork ${ }^{\circledR}$, etc. However, these systems are universal and are used either separately or integrated via files or standardized communications interface. The application of the systems to the management of WSS reconstruction project is complicated by the following features of these projects:

- a significant number of simultaneously running projects;

- different specific resources involved in project implementation;

- variability of the projects environment;

- the need for taking into account values delivered by projects.

The value-driven project management now is only being developed. For example in the wellknown G. Kerzner and F. Saladis work "Value driven project management" the concepts of value driven project management are only postulated [15]. All mentioned above determine the need to develop solutions that would allow effective value-driven management of WSS reconstruction projects with the help of DSS.

The main aim of the article is to develop the models of the system for value-driven decision support in project management of water supply systems reconstruction and development. The effective work and use of such a system is determined by the presence of tools for assessing the status of ongoing projects in portfolio and estimating result in creating business value.

\section{THE METHODOLOGY FOR DECISION SUPPORT IN WSS RECONSTRUCTION PROJECTS}

The difficulty of assessing the status of ongoing projects is that the attributes of reconstruction projects usually are not clearly specified, qualitative and vague. In addition, the complexity of assessing the value that each project implementation adds to city municipalities complicates the problem solution.

In this context, the determination projects states, in fact, is the task of recognition and classification directed to relation a recognizable image to a known class. The initial data for the solution of classification problems are the limited amount of sample data about the project attributes values that describe the classified situation. One of the goals of classification is to determine the relationship between the signs and symptoms of the classified object class and study this relation. To determine the relationship between the features correlation analysis or artificial neural networks (ANN) are usually used [16]. In this case the ANN has the advantage that it is not programmed and can be trained. Neural networks with error back propagation are the most widely used in classification and pattern recognition. In the simplest case - the single-layer ANN $Y$ can be represented by two: vector $X$ of input signals and vector $K$ of coefficients as follows:

$$
Y=\sum_{i=0}^{n} x_{i} \cdot k_{i}
$$

To solve the problem of estimating the effect of the implementation of each project requires the use of mathematical tools that provide some generalized value as an integral evaluation of each project. Based on the fact that each project is aimed at improving the quality of some services, there is a possibility of comparing parameters of the project so that it will be possible to choose projects that will help achieve the best system performance. It may involve a variety of methods, one of the most simple and effective - weighted sum method, which allows to take into account the values of the individual parameters of the projects, and the contribution of these values to the integral value of assessing the projects impacts [17]. For simplicity, we assume that the weight of the criteria set by experts as project types, project priorities and customer types.

Based on the fact that each project is devoted to creating a higher quality of service, there is the possibility of comparing the parameters of the projects in such a way that it will be possible to choose projects that will help achieve the highest business value. For simplicity, we assume that the weights of the criteria are given by experts and are defined as priorities of projects, their types and types of stakeholders. Therefore this weighted sum will be represented as follows:

$$
Y_{i}=w_{0 i} *\left(w_{1} * w_{2} * \sum_{r=0}^{R} w_{3 r i} * p_{r i}+w_{4} * \sum_{j=0}^{J} w_{5 j i} * u_{j i}\right),
$$

where $Y_{i}$ - integrated evaluation of the project, $w_{0 i}$ - weighting assessment of the project, $w_{1}, w_{2}, w_{3}, w_{4}, w_{5}$ - the weights determine the priority of projects, project declared technological parameters, priority sites and the parameters measured on it, respectively, $p_{r i}$ - the value of declared parameter $r$ of the project $i, u_{j i}$ - the value of declared critical parameter $j$ of the project $i$. 
Weighting factor of a project can be calculated as:

$$
w_{0 i}=\left\{\begin{array}{l}
1, \text { if a project should be envolved } \\
f(i), \text { if a project can be excluded }
\end{array},\right.
$$

where $f(i)$ - weighting factor evaluation function, obtained as a result of ANN work, $f(i)=[0 . .1]$. If $f(i)=0$ then a project have to be stopped. If $w_{0 i}=1$ than a project should be added to current portfolio while if $w_{0 i}<1$ then it can be excluded from the portfolio.

Thus, it is possible to implement a decision support in municipal water supply reconstruction projects classification and ranging on the basis of integration the use of ANN and weighted sum method.

Integral project value assessment allows taking into account its social aspects. But it is also necessary to take into account economic aspects, i.e. to dispose enterprise resources in such a way that get the best effect from projects implementation. Thus we have to form project portfolio on the basis of information about available resources. This problem can be reduced to the well known knapsack problem: we have to place maximum possible number of valuable items in a fixed volume knapsack, taking into consideration that the total weight of all items that can fit in a knapsack, is limited.

Let $P=p_{1,} p_{2}, \ldots p_{i}-$ will be the set of projects, $x_{t 1}, x_{t 2}, \ldots x_{t i}$ - are income from each project at time $t, y_{t 1}, y_{t 2}, \ldots y_{t i}-$ investments in each project in time $t, r$-discount factor, that does not depend on $t$. Then weighted integral project value considering their social value may be written as functional:

$$
S=\sum_{i=1}^{I} \sum_{t=0}^{T}\left(\frac{Y_{i}\left(x_{t i}-y_{t+1, i}\right)}{(1+r)^{t}}\right) .
$$

Let $C_{1}, C_{2}, \ldots C_{n}$ - will be the set of available resources. Thus the task for project portfolio formation can be stated as follows: we have to find the set in $I$ that allowing to maximize $S$ taking in the account the restrictions for $C_{1}, C_{2}, \ldots C_{n}$, where $n \in$ $1 . . N, N-$ the quantity of resource types. If we will use brute force we will need to consider $2^{I \cdot T \cdot N}$ variants.

\section{DESIGN AND IMPLEMENTATION OF SOFTWARE FOR DSS IN THE WSS RECONSTRUCTION PROJECTS}

In order to provide opportunities for horizontal integration of DSS subsystems and the vertical integration of DSS itself with project management system, we shall introduce different models that will integrate mechanisms and tools for integration of the subsystems into a single DSS. Vertical integration of the DSS information system into the city's information infrastructure is directly connected to providing stakeholders with access to the system and should not require significant system modification. This problem can be solved by providing remote access to the system resources for other clients of the system via a local network or the Internet with the use of secure communication protocols for data transfer and control between the subsystems.

Taking it into account, the following structural model of an automated DSS for ranking projects of WSS reconstruction and development is suggested (Fig. 1). In the model there are packets "Environmental parameters", "Planned projects", "Ongoing projects", "Projects Resources", "Projects assessment", "Projects value evaluation", "Projects ranking", "Projects implementing".

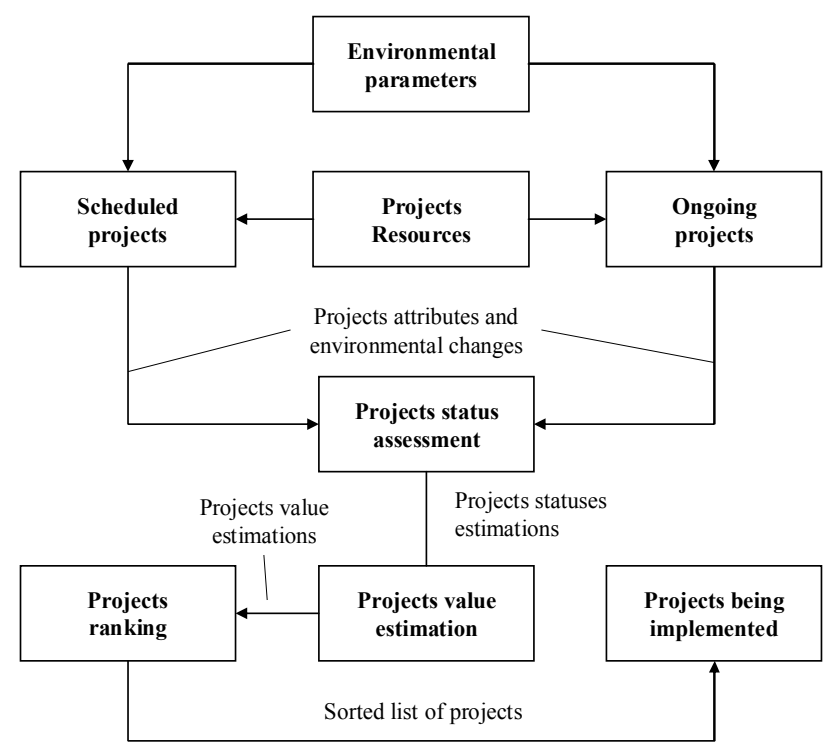

Fig. 1 - Structural model of an automated DSS for projects ranking.

Package "Environmental parameters", "Ongoing projects" and "Scheduled projects" should provide storage and tools for measuring and processing parameters of reconstruction projects, their resources, environment etc. Package "Projects Resources" stores information and provides tools for its processing resources projects and the organization as a whole. Package "Projects status 
assessment" must carry out the assessment of the current state of the projects based on the values of attributes of projects and generate value of the evaluation function as a number between 0 and 1 , which will be used as coefficient when calculating the effectiveness of projects. Package "Projects being implemented" will contain the sorted list of projects arranged for implementation. In accordance with the advantages of the architecture MVC, these subsystems may be arranged as shown in Fig. 2.

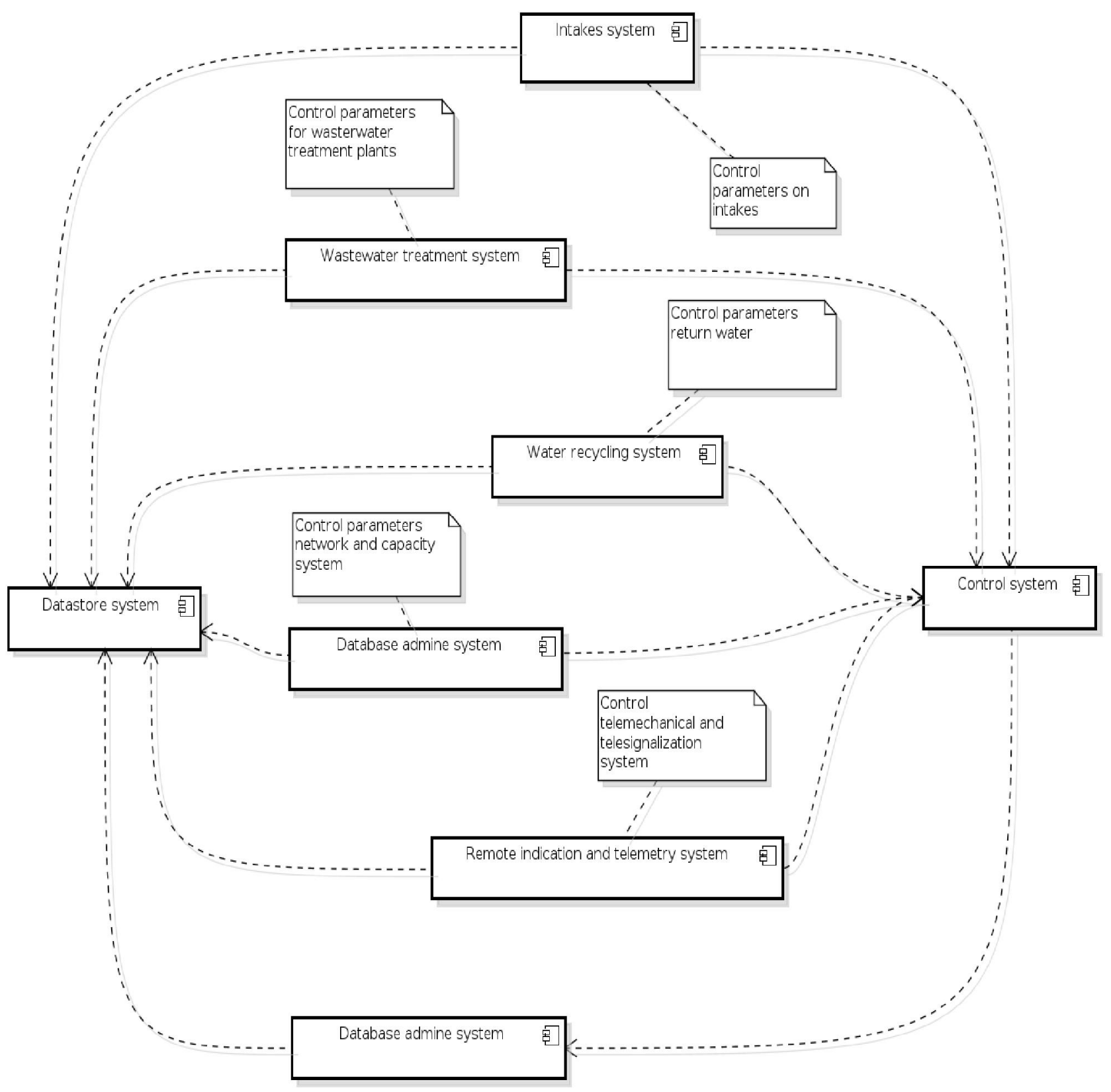

Fig. 2 - Component model of the DSS according to the MVC architecture.

Based on the description of the system and a list of parameters to be monitored and measured, the model of the system data as a class diagram was developed. The class diagram in UML notation is shown in Fig. 3. On the basis of systems structural model (Fig. 1) and taking into account data model presented (Fig. 3) the application of the DSS for WSS reconstruction projects classification and raging was created. Example of a window form is shown on Fig. 4.
Testing the status of the project by means of an ANN was carried out with the help of the module that is based on a graphical representation of the data distribution works "reliability" of each project to the basis of the data about projects types, jobs and the necessary technological units. The data obtained from the ANN qualifier were transformed into diagrams of distribution of density of estimates of projects statuses (Fig. 5). The diagrams were created with the help of the GnuPlot program. 


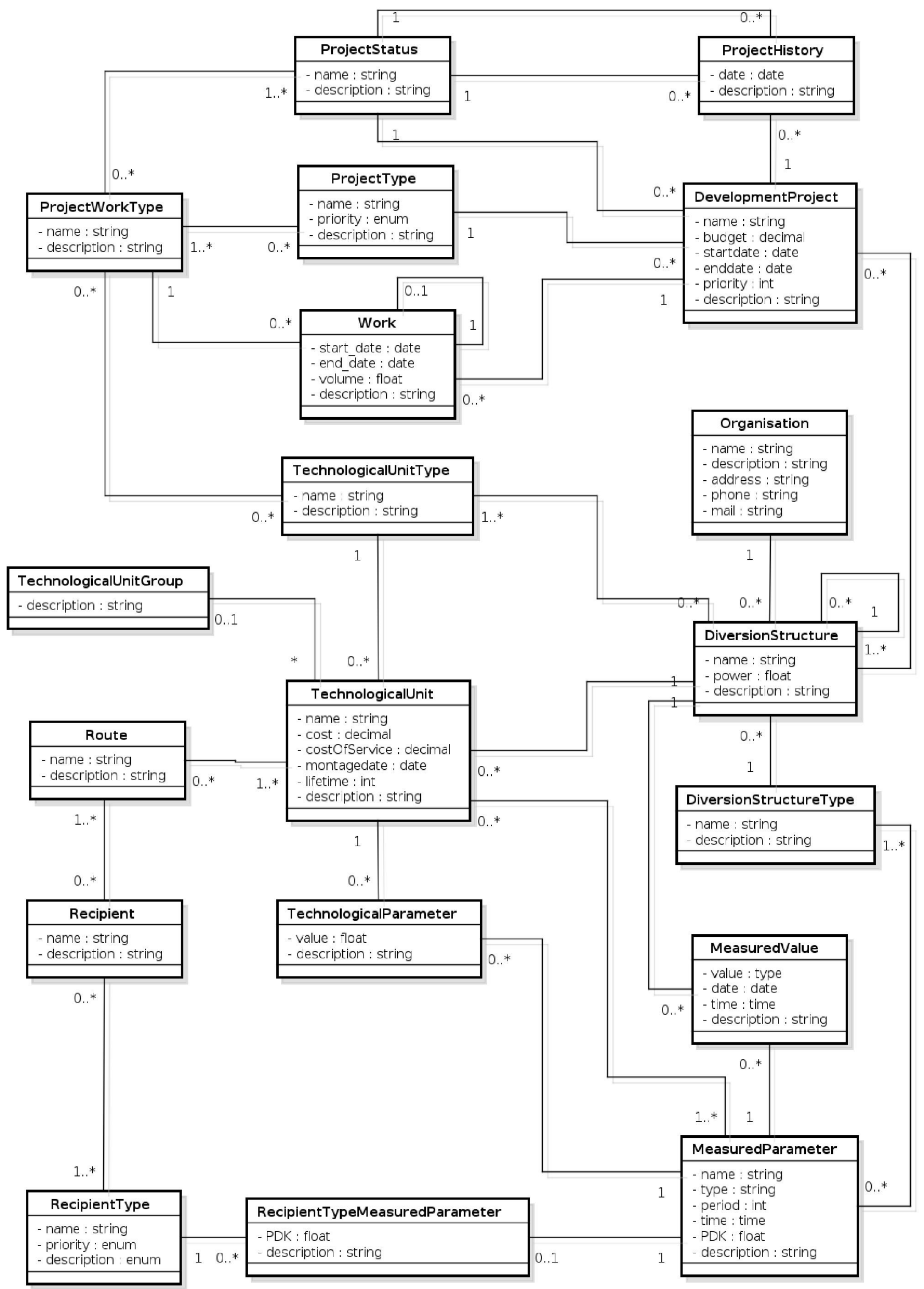

Fig. 3 - Information system class diagram. 


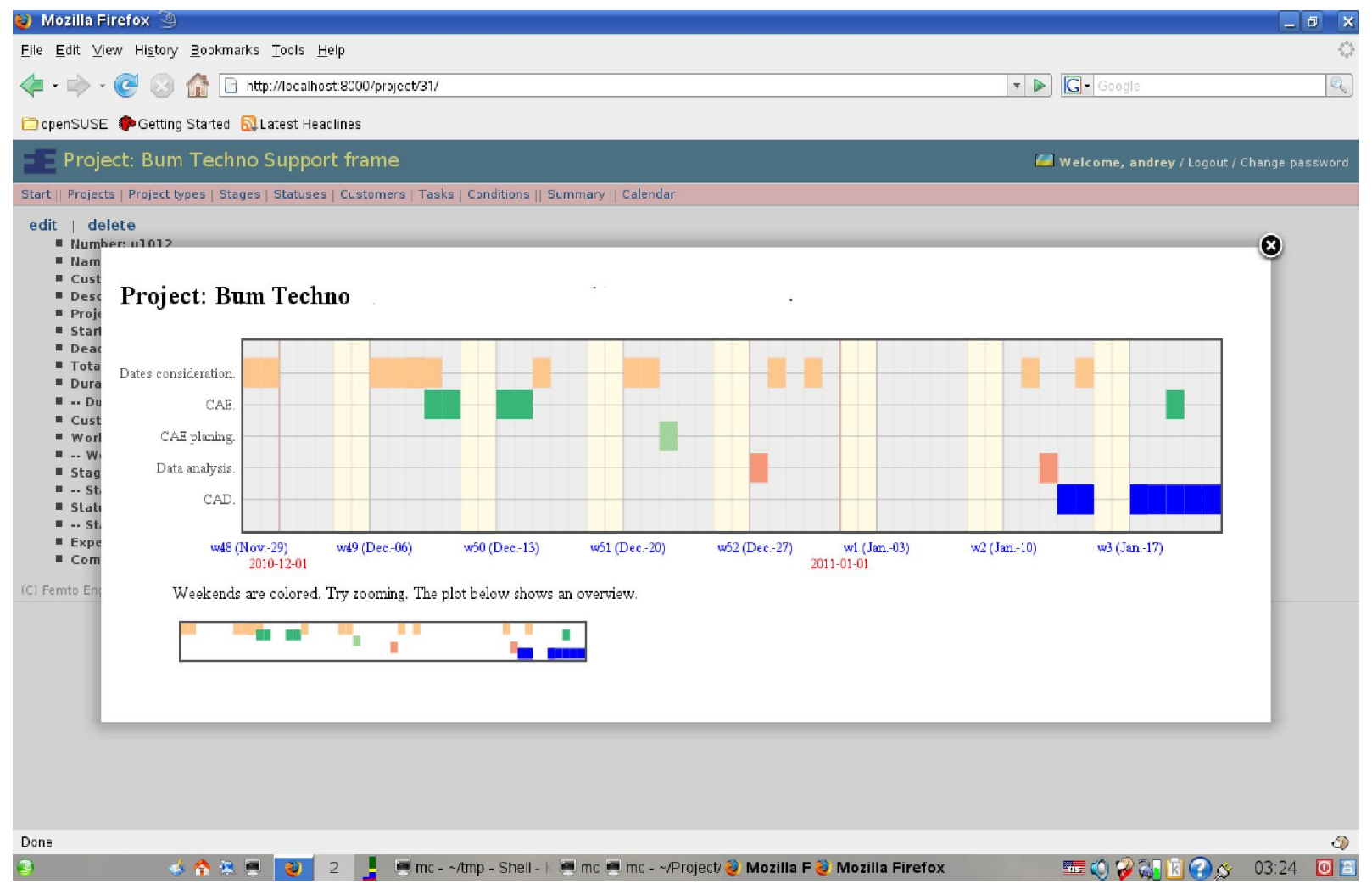

Fig. 4 - The representation of WSS reconstruction projects portfolio.

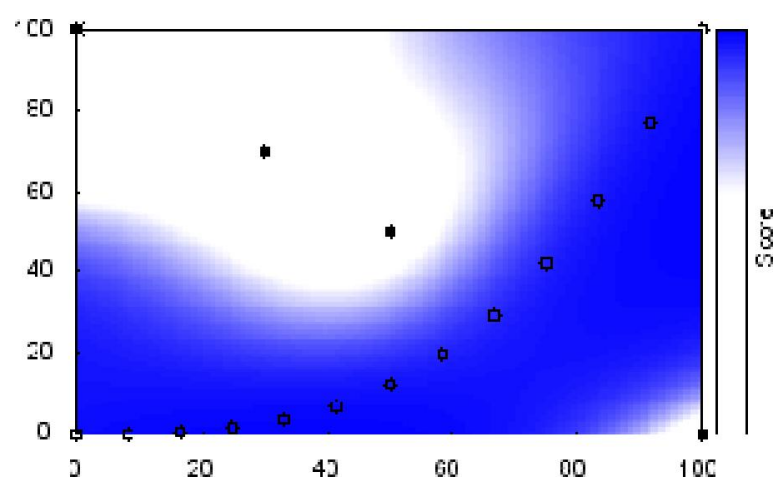

Fig. 5 - Graph of the evaluation of density distribution for a project.

\section{CONCLUSIONS}

According to the analysis, the concept and appropriate models of the DSS in WSS reconstruction projects classification, ranging and optimization were developed. In order to improve the effectiveness of managerial decision the distributed DSS including a database server, an application server and client terminals was developed. The software based on the use of artificial neural network with back propagation, weighted sum method and the model for adding projects to portfolio based on the information about available resources allows to reduce project schedules and increase the efficiency of communication between project stakeholders. All models and tools are implemented in the opensource free distributed OS Linux.

\section{REFERENCES}

[1] Vital water graphics: An overview of the state of the world's fresh and marine waters, $2^{\text {nd }}$ Edition, 2008. http://www.unep.org/dewa/ vitalwater/article141.html.

[2] G. J. Browder, S. Xie, Y. Kim, L. Gu, M. Fan, D. Ehrhardt, Improving the Performance of China's Urban Water Utilities, The International Bank for Reconstruction and Development / The World Bank, 2007.

[3] Harbin Water Supply, Project Reference Number: PPE: PRC 2010-79 Project Number: 33177 Loan Number: 1995, People's Republic of China, December 2010.

[4] Municipality of Thames Centre Water and Wastewater Master Plan Class Environmental Assessment, Report Project Number: 2984.01, K02890201, Date: November 3, 2008.

[5] Public-supply water use, http://water.usgs.gov/ edu/wups.html.

[6] About the main indicators of the water economy of Ukraine in 2011, Statistical Bulletin, Ukrainian State Statistical Committee, 30.03.2012, No. 3, 3-52. 428 p. (In Ukrainian) 
[7] National Report: The quality of drinking water and the situation of drinking water in Ukraine, 2011, http://minregion.gov.ua/attachments/ files/zhkh/Vodopostachannya/. (in Ukrainian)

[8] Community public water systems design criteria, Division of Water Supply, Tennessee Department of Environment and Conservation, 2008.

[9] Water distribution system design guidelines and standard specifications and details, http://dpuserver.drivehq.com/waterdistribution guidelines_specifications.pdf.

[10] K. T. M. Formiga, F. H. Chaudhry, P. B. Cheung, L. F. R. Reis, Optimal Design of Water Distribution System by Multiobjective Evolutionary Methods, http://www.bwd.com. $\mathrm{br} /$ geasd/fotos/geapublicacoes1.pdf.

[11] N. G. N. Mohammed, A. Abdulrahman, Water Supply Network System Control Based on Model Predictive Control, http://www.iaeng. org/publication/IMECS2009/IMECS2009_pp1 172-1177.pdf.

[12] Latest Technologies in Supervisory Control Systems for Water Supply and Sewage Services, http://www.yokogawa.com/us/technical-library /white-papers/latest-technologies-in-supervisor y-control-systems-for-water-supply-and-sew.

[13] Moscad Application Note, http://www.adut.hr/ scadadocs/Literature/ApplicationNotes/MOSC AD\%20in\%20Water\%20Systems.pdf.

[14] Improvement of Water Supply through a GIS Based Monitoring and Control System for Water Loss Reduction, http://www.un.org/ waterforlifedecade/green_economy_2011/pdf/s ession_5_technology_cases_burkinafaso.pdf.

[15] H. Kerzner, F. Saladis, Value-Driven Project Management, John Wiley \& Sons and IIL Publishers, 2009, $276 \mathrm{p}$.

[16] S. Haykin, Neural Networks, Full course, Moscow, LLC "Publishing House Williams", 2006, 1104 p. (in Russian)

[17] O. I. Larichev, Objective Models and Subjective Decisions, Moscow, Nauka, 1987. (in Russian).

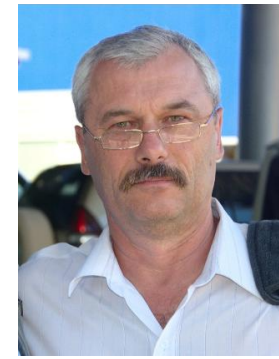

Anatoliy Gaida, Ph.D. graduated with Master degree in Electrical Engineering at National University of Shipbuilding, Ukraine. He works as Ass. Prof. at department of Informational Control Systems and Technologies in the National University of Shipbuilding. Research area: Project Management,

Information Technology.

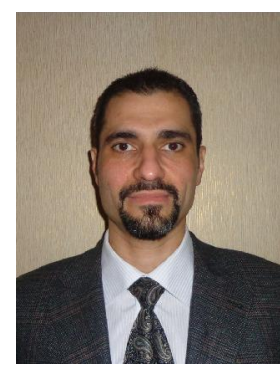

Tigran Grigorian, Ph.D. graduated with Master degree in Shipbuilding at National University of Shipbuilding, Ukraine. Now he works as Ass. Prof. at Project Management Department in the National University of Shipbuilding, Ukraine. Research area: Value-Driven Project Management, Knowledge Management.

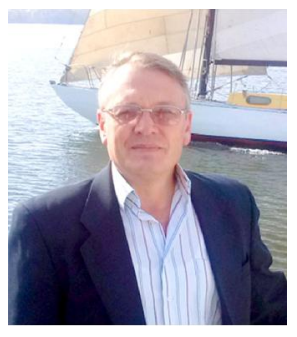

Yuriy Kharitonov, Prof. Dr. Sci. Tech., graduated with Master degree in Machinery at National University of Shipbuilding, Ukraine. Now he works as Dean of the Faculty of the National University of Shipbuilding. Research area: Project Management.

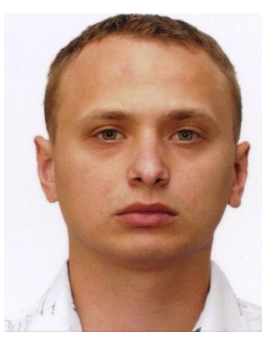

Volodymyr Koshkin, Master of project management (National University of Shipbuilding, Ukraine); Master of computer science (Glyndwr University, Great Britain (United Kingdom). Now he is post graduate student of the project management department of the

National University of Shipbuilding. Research area: Decision support system and technologies in municipal economy. 